\title{
AC 2012-4591: TCNJ ADVANCE PROGRAM (TAP): ASSESSMENT AND FACULTY DEVELOPMENT INITIATIVES FOR FOSTERING CAREER ADVANCEMENT WITHIN A PUI ENVIRONMENT
}

\section{Dr. Karen Chang Yan, College of New Jersey}

Karen C. Yan is an Associate Professor in the Mechanical Engineering Department at the College of New Jersey. Her teaching and research interests include biomaterials with tissue engineering applications, composite materials, and materials science.

\section{Dr. Lisa Grega, College of New Jersey}

Dr. Suriza VanderSandt, College of New Jersey

Suriza Van der Sandt conducts research in the broad area of pre-service mathematics teacher education. Her research interests include geometry teaching and learning, focusing on spatial orientation and spatial insight. More recently, she has also conducted research on factors influencing teaching and learning of pre-service mathematics teachers (e.g. mathematics anxiety), as well as factors affecting observational learning (e.g. self-efficacy and outcome expectations). Van der Sandt's teaching covers both pure mathematics and mathematics education. Pure mathematics courses include Calculus and Applied Liberal Art Mathematics. Mathematics education courses include both content courses and methodology courses specifically designed for education students: e.g. Mathematical Structures and Algorithms for Educators; Perspectives on the Development of Mathematics; Teaching Mathematics in the Early Childhood and the Elementary Classroom; and Patterns, Functions, and Algebra for Middle School Teachers. She regularly visits schools to observe senior mathematics education majors during their student teaching.

Dr. Diane C. Bates, College of New Jersey

Dr. Elizabeth Borland, College of New Jersey

Elizabeth Borland is an Associate Professor of sociology at the College of New Jersey. She conducted qualitative research on faculty gender equity as part of the NSF-funded TCNJ Advancement program.

\section{Dr. Karen Elizabeth Clark, College of New Jersey}

Karen Clark is an Associate Professor in the Department of Mathematics and Statistics at the College of New Jersey.

\section{Dr. Amanda Norvell, College of New Jersey}




\title{
TCNJ ADVANCE Program (TAP): Assessment and Faculty Development Initiatives for Fostering Career Advancement Within a PUI Environment
}

\begin{abstract}
The scarcity of women at the full professor level of academia in STEM disciplines is a wellknown problem experienced by colleges and universities nationwide. Primarily undergraduate institutions (PUI) like The College of New Jersey (TCNJ) are no exception to this trend. Furthermore, female faculty here face unique challenges including a short tenure clock (4 years), promotion to Associate Professor being a separate application process from tenure, and high teaching and service loads with no graduate student support.

In September 2009, TCNJ was awarded an ADVANCE PAID award to address the issues of female faculty advancement and stalling in rank in the STEM disciplines. The TCNJ Advancement Program (TAP) was created with the support of the ADVANCE award. TAP combines both equity assessment and faculty development initiatives in order to understand barriers to career advancement within TCNJ's PUI environment and to create programs to foster them. In the equity assessment initiatives, a comprehensive faculty database has been created which can identify differences among STEM and non-STEM disciplines in the amount of time faculty spend at rank. Qualitative interviews were also conducted to identify potential barriers faced by women. The faculty development initiatives encompass a broad spectrum of mentorship, professional development, and family friendly practices. Both external mentorship and internal mentorship programs were developed and implemented to provide a circle of mentors for female faculty. A multi-facet approach was taken for the professional development initiatives including organizing workshops, travel grant program, and formal and informal networking activities. The Family Friendly Initiatives focus on two areas: a Modified Duties Policy and the recruitment and retention of dual career couples. Current family friendly policies at TCNJ were reviewed by an ad hoc committee and the process of developing a formal Modified Duties Policy was initiated through the College governance process.
\end{abstract}

\section{Introduction}

There is continuing concern about gender inequality in science, most recently documented by the National Academy of Sciences ${ }^{1}$. Its report finds women are increasingly represented as undergraduates, and among doctorates (30\% for more than thirty years in the social sciences; $20 \%$ in the life sciences), but they are not advancing up the faculty ranks. In fact, at top research schools, only about 15 percent of full professors in the sciences are women, and minority women are "virtually absent"1.

While the literature suggests that overt discrimination is less common on campuses today, scholars increasingly recognize subtle "push" and "pull” factors that disadvantage women and favor men ${ }^{2}$, and translate to allocative discrimination ${ }^{3}$, bias that affects opportunities for promotion and, therefore, salaries. Problems with allocative discrimination remind us that gender 
is embedded in organizational practices and processes ${ }^{4}$. Qualitative research points to institutionalized barriers for women and minorities, including a lack of mentorship and camaraderie, severe time demands (particularly for mothers), and problems gaining credibility ${ }^{2,5}$.

While this research paints a clear picture of the continuing problem facing women in science disciplines, it also points to avenues for improvement: the institutional nature of gender schemas means that there are opportunities for institutional — rather than just individual— change. "Organizational catalysts" and "institutional intermediaries" campuses to challenge policies and practices that produce and reproduce gender inequality.

\section{Institutional Background}

The College of New Jersey (TCNJ) is a highly selective, public, primarily undergraduate institution (PUI) that has earned national recognition for its commitment to excellence. Founded in 1855, TCNJ has become an exemplar of the best in public higher education and is consistently acknowledged as one of the top comprehensive colleges in the nation. With about 300 members of the full-time teaching faculty and roughly 6200 undergraduate students, TCNJ prides itself on its teacher-scholar model.

At TCNJ, gender equity issues reflect some national patterns but appear more equitable than national averages on other issues. TCNJ currently has 14 departments within the physical, social, and behavioral sciences, engineering, and economics. Faculty members in NSF-supported disciplines constitute 137 (37\%) of the 369 full-time faculty members at TCNJ in Academic Year 2007-08, and women represent $40.9 \%$ of faculty in all NSF-supported disciplines. New faculty recruitment in the past fifteen years has sought to maintain or improve some of these imbalances: 44.8 percent of new hires in Science, Technology, Engineering, and Mathematics (STEM) disciplines were women, as were 64.3 percent of new hires in the Social, Behavioral, and Economic (SBE) science disciplines.

Despite the relatively high level of representation of women in NSF-supported disciplines at TCNJ, female faculty members have faced difficulty achieving promotion to associate and full professor, as our initial data analysis suggests that women in NSF-supported disciplines are stalling at rank when compared to other faculty at TCNJ. Unique challenges at TCNJ have been identified as following:

1. TCNJ has an unusually short "tenure clock": new faculty members apply for tenure in their fourth year.

2. Tenure review and promotion to associate professor are two separate processes. Faculty members may remain at the assistant professor level long after receiving tenure.

3. As a public PUI, typical teaching and service loads are $18 \mathrm{FWHs}$ (3FWH for a typical lecture course) and $6 \mathrm{FWHs}$ per year respectively. There is no graduate student support for research and teaching.

As of 2008 (prior to the ADVANCE award) among faculty who have been at TCNJ for at least five years in the STEM disciplines, 11.9 percent of men and 23.8 percent of women 
remained at the rank of assistant professor. This pattern was more pronounced at the rank of full professor: in STEM disciplines, 50.0 percent of men and only 14.3 percent of women have achieved this rank. These differences in rates of promotion result in a gender imbalance at higher ranks in NSF-supported disciplines at TCNJ. In STEM disciplines, women constitute 45.2 percent of associate professors, but only 11.5 percent of full professors. In comparison, among TCNJ faculty in disciplines not supported by the NSF, women make up 50 percent of full professors. There were no full female professors in the School of Engineering, or in the departments of Biology, Computer Science, Economics \& Finance, Physics, Political Science, or Sociology \& Anthropology.

\section{Program Goals and Initiatives}

To address the issues of female faculty advancement and stalling in rank in the STEM disciplines, in September 2009, TCNJ was awarded an ADVANCE PAID award. The overarching goal of TCNJ Advancement Program (TAP) is to develop a comprehensive model for career development through several initiatives. Specifically, TAP combines both equity assessment and faculty development initiatives to understand and facilitate career development within TCNJ s primarily undergraduate environment.

The Equity Assessment Initiative represents the foundation of TAP. A comprehensive faculty database will provide an accurate picture of differences in advancement between male and female faculty and will enable faculty progression through the ranks to be tracked for long term assessment. Climate surveys and interviews of current associate and full professors will identify barriers faced by female faculty.

The Faculty Development Initiatives consist of programs and policies which provide opportunities for career development. A multi-faceted approach was taken, the corresponding program initiatives encompass peer mentorship, professional development, and family friendly policies.

As TCNJ is in the 3rd year of this 3-year NSF funded ADVANCE PAID grant, this paper will discuss the implementation of the program initiatives and success and challenges learned in detail.

\section{Equity Assessment Initiative}

\section{Faculty Database}

A longitudinal faculty database was constructed in coordination with Human Resources, The Center for Institutional Research and Academic Affairs. Original HR data contained incorrect information and lacked promotion data. In analysis of the data, only faculty hired after 1990 were included. The reason for excluding pre-1990 data is that standards for promotion changed at around this time period. Faculty hired after 1990 were expected to establish a research program and publish, which became an additional criteria for tenure and promotion.

Based on analysis of this dataset, it was found that women faculty in STEM disciplines (excluding engineering) took over 2 years longer to achieve the rank of full professor than their 
male colleagues. Women in SBE disciplines took over 3 years longer. In contrast, women in the professional schools (Education, Business (excluding economics), and Nursing Health \& Exercise Science) take just .07 years longer than their male colleagues and women in the Arts and Humanities take only .33 years longer than their male colleagues to achieve the rank of full professor. These data suggest that women, particularly in the NSF-supported disciplines are stalling at rank, although the stall occurs for women in STEM disciplines more often in the rank of assistant and for women in the SBE disciplines at the rank of associate. Women in the social behavioral and economic sciences spend on average 2.5 years longer at the rank of associate than their male colleagues, and nearly 5.5 years longer at TCNJ before earning rank of full. There are no statistically significant differences between men and women in some of the STEM disciplines (School of Engineering). In Engineering, women associates have spent an average of 6.4 years at TCNJ, while men have spent 6.00; in Science, women have spent 12.60 years at TCNJ while men have spent 9.00 years. It should be noted that there have been no full female professors in the School of Engineering. While there have been female faculty in Engineering during the 1990’s, the most senior female faculty member in this school was hired in 2001.

The faculty database is updated on an annual basis and will be expanded in the future. Plans include incorporating analysis of service obligations, data stored on Digital Measures, and information regarding individuals who have left campus. Digital Measures is an online database in which faculty enter information regarding their activities during each academic year and publication and presentation information. It was introduced on campus about three years ago and can thus make more detailed analysis of faculty accomplishments according to gender, discipline, and length of service.

\section{Qualitative Interviews}

Research for the Gender Equity Interview Project was carried out in Fall 2010 and an analysis of the data was performed in Spring 2010 to identify policies and practices that produce and reproduce gender inequality. All of the female professors and a comparable number of male full professors from NSF-supported disciplines were asked to participate in interviews about their career histories, with particular attention to the process of promotion to full professor (see Table 1 for sample information). All of the female associate professors eligible to apply for promotion and a comparable group of male associate professors were also asked to participate.

Table 1: Sample Information for Gender Equity Interview Project

\begin{tabular}{|c|c|c|c|}
\hline & Population & Invited & Interviewed \\
\hline Male Full & 30 & $14^{*}$ & 10 \\
\hline Female Full & 10 & 10 & 10 \\
\hline Male Associate & 15 & 12 & 4 \\
\hline Female Associate & 12 & 12 & 8 \\
\hline TOTAL & 67 & 44 & 32 \\
\hline
\end{tabular}

*From the original random sample, six full professors agreed to be interviewed. To make up for this deficit, an additional four male full professors from the same departments as those who declined (the person with the hire date nearest to the decliner) were asked to participate and agreed to do so, resulting in a total of 10 interviews with male full professors. There were no replacements for the associate professors who declined. 
The response rate for the study was 73\%, and was better for full professors than associate professors. For the total population, men had been teaching full time for about 5 years more on average (17.5 years vs. 22.5 years). For the sampled group of associates, averages were higher: women had taught 19.71 years while men had taught 29.2 years. Thus, the sampled population of male associates had disproportionally more years teaching full time than the sample of female associates, and seems less representative of the whole population of male associates than the other groups.

The interviews asked professors to provide a detailed career history, with particular attention to the decision to apply (or not to apply) for promotion to full professor. Interviews were professionally transcribed and all identifying material was removed before analysis.

Overall, there was little evidence of overt harassment or discrimination of women at TCNJ, and there was no evidence of differential allocation of resources by gender. Men and women were equally likely to have received mentorship on campus. On average, women full professors took nearly three years more than men to achieve their rank (14.5 years at TCNJ for women vs. 11.8 years for men).

The analysis highlights four thematic areas related to gender equity. First, women were more likely to have been actively discouraged from applying for promotion, and expressed more ambiguity about how their work was valued by their colleagues. Second, TCNJ's short tenure was seen a particularly problematic by the women interviewed, most of whom were mothers and either had babies or young children pre-tenure or soon after tenure. Third, the service burden of acting as department chair was hard to balance with scholarship; women were more likely to report that they had been coerced into service positions, and women who had acted as department chair when they were associate professors were less likely to gain promotion than their male counterparts. Fourth, women were more likely to report that they felt isolated since they had a lack of time to reach out to others. This was often discussed in conjunction with family obligations that constrained their time on campus.

\section{Mentorship Programs}

The mentorship initiative consists of an external mentorship program, modeled after Hunter College's Sponsorship Program, and an internal faculty mentorship program, which emphasizes the development of a circle of mentors, similar to University of El Paso's program. Both programs have been developed and implemented since 2010.

\section{External Mentorship}

In a primarily undergraduate institution such as TCNJ, a faculty member might be the only person or one of a very few people in a specific subfield. Access to successful senior faculty in one's field is very limited, and this can make a large difference in one's scholarship development. The objective of the external mentorship program is to allow female faculty (associates) to be mentored by an external sponsor; that is, an individual who is highly recognized in the associate's field and can provide support in helping her develop her research program. 
The external mentorship program was initiated in Spring 2010. A Request for Proposals (RFP) was developed and sent to all eligible faculty members (Only female full time tenured or tenure-track faculty at the rank of Assistant or Associate Professor in NSF-supported disciplines were eligible to apply.) In addition to announcing the program via email, the program was also promoted through the TAP website. Upon receiving the applications, the TAP committee reviewed the applications and made award recommendations. The awardees selected the most appropriate sponsor based on geographic proximity and research goals after discussion with the TAP team. Contracts for external sponsor's compensation (\$5000) were also developed, and the awardees started working with their sponsors in September 2010.

The following spring, the previous Request for Proposal (RFP) was examined and modified according feedback received. A new peer review process was developed and implemented. In particular, we reached out to colleagues in the STEM disciplines on campus and invited them to review the applications received, which in turn broadened participation for the TAP program. The RFP was posted on the TAP website, and sent to eligible faculty members directly. A question and answer session was held during one of the Brown Bag Lunch (BBL) series, and also invited the awardees to share their experience/insight.

In order to evaluate the effectiveness of the program, two surveys were developed and conducted: one survey for collecting the baseline data on the associate's scholarly activities during the year prior to the award, and the other (online) for collecting information on the interactions between the associates and the sponsors and the associate's scholarly activities during the award period. In both cases, we had $100 \%$ response rate. Exit interviews were recently completed and are currently being analyzed.

During the two award cycles, eight applications were awarded. Among them, four were from pre-tenured assistant professors, and the other four were from tenured associate professors. The awardees were from five departments in both STEM and social science areas. As the number of applications was relatively low, the TAP team is currently seeking feedbacks from all eligible faculty in this regard and forming strategies to further increase participation.

\section{Internal Mentorship}

The goal of TAP's faculty mentorship program is to enable female faculty to develop a circle of mentors, which would include faculty mentors both inside and outside of her department. In addition, mentorship is extended to include faculty at the associate professor level, who are mentored by full professors. In order to have this program blend as seamlessly as possible into existing departmental mentorship programs, assessment of current mentorship programs in departments was initially conducted, which included a survey sent to department chairs from which information was collected on any current mentoring programs. Within the NSF supported disciplines, no mentorship programs existed in the School of Engineering or in Political Science. Of the departments with mentorship programs, most were rather informal in nature, in which matches were assigned by the department chair and each mentee assigned a single mentor. Mentorship typically only lasted through tenure. 
In order to optimize the matching process, online profile surveys were sent to mentors and mentees, in which mentees indicated areas they sought mentorship and mentors indicated areas they felt qualified to offer mentorship. In the first year, about one third of the eligible female faculty participated, with about one third of those being associate professors. A brown bag lunch was initially held for mentors and mentees. This served as an introduction to the program. Two workshops related to mentorship were held since then. After the first year, a survey was distributed to the participants to gauge the extent of their interactions during the academic year. All of the mentors who responded indicated that they had some interaction with their mentees; the most infrequent response was once per month. All of the mentees who responded except for one indicated that they had some interaction with their mentor.

\section{Professional Development Programs}

The main programs which are being implemented under this initiative are the Travel Grant program, the Annual Symposium, a Brown Bag Lunch series, and a series of Professional Development Workshops.

\section{$\underline{\text { Travel Grant }}$}

The travel grant program was developed for the purpose of enhancing the research activities of women in NSF-supported disciplines and increase their visibility in various research venues. Only female full time tenured or tenure-track faculty at the rank of Assistant or Associate Professor in these disciplines were eligible to apply. The Review committee consisting of members of the TAP Team evaluated the eight received proposals on their merit. The selection was competitive with six grants awarded during the first offering, some partially funded. Each applicant is expected to provide a report of activities and benefits to the individual's academic career.

In the second offering, thirteen female faculty from a variety of disciplines applied for travel funding. All applications consisted of a 1 to 2 page proposal that included information about the applicant's rank, the proposed conference, relevance to the applicant's research area and possibilities for networking, as well as a detailed and realistic budget including pending sources of income from other sources. The applications were reviewed by a panel consisting of (non-voting) ADVANCE grant team members, Dean, faculty members. Five applicants each received a grant of $\$ 1000$. The applicants were required, upon returning from the conference, to submit a short paragraph on how attending the conference of their choosing benefitted their research.

\section{$\underline{\text { Annual Symposium }}$}

The first symposium was held on 7 October 2010 and was co-sponsored by the TCNJ Politics Forum. There were twenty six TCNJ faculty in attendance, along with a large number of students. Dr. Virginia Zakian, Professor of Life Sciences, Department of Molecular Biology, Princeton University, gave the keynote presentation, entitled "A Career in Science: Making the right choices". The talk was well received by both faculty and students. The office of the Provost sent out invitations to the TCNJ campus as well as to seven tertiary institutions in the state. The Provost, and first year travel grant and mentorship awardees also shared their 
experiences. The symposium concluded with some networking opportunities. At the end of the event attendees were requested to complete a survey evaluating the different parts of the event. The vast majority of the attendees found the speaker engaging and found the networking opportunity useful in making contact with other women in science. A suggestion was made to include a panel discussion in future symposiums.

The second annual symposium was held on 20 May 2011. Dr. Nancy Cantor, Chancellor and President of Syracuse University, gave the keynote speech. Her presentation, entitled "Gender Equity in the Sciences: Forging a Third Space” was well received and was followed by a panel discussion on "Gender Equity in the Sciences". The panel consisted of two TCNJ female faculty who are at the rank of full professor and two female faculty from other tertiary institutions in TCNJ. The panel discussion was very well received by attendees and the time scheduled for this part of the symposium will be lengthened in future symposia. Attendees rated this symposium higher than the first year with the panel discussion receiving most praise.

\section{Brown Bag Lunches}

Two brown bag lunches are held every semester. Topics included mentoring; working with special needs students (Director of Office of Differing Abilities led the brown bag lunch); balancing family and work life; applying for an External Mentorship Grant; and leadership. Faculty seem to enjoy attending these as they are conducted in a very low key and informal manner. At the conclusion of each brown bag lunch attendees were requested to complete an evaluation survey that was used to inform the nature/composition and topics of future brown bag lunches. In response to suggestions in the evaluations we have rotated the day of the week that the lunches are held, so that more faculty are able to coordinate with their teaching schedules.

\section{Professional Development Workshops}

Two workshops are held every semester. The format for the workshops and many of the topics were adapted from the format and topics of Hunter College's faculty workshops which were developed under their Gender Equity Project (GEP). Dr. Annemarie Nicols-Grinenko, GEP director, was consulted during the planning of the workshop and participated in it by presenting the workshop on Developing a Circle of Mentors. A list of all of the workshops held during the past academic year can be found in Table 2.

The targeted audience for these workshops has been assistant and associate professors in the NSF supported disciplines. As the Promotions workshop was relevant to all TCNJ faculty, all faculty were invited to this workshop. The first two workshops were attended by all female faculty, while the last two were attended by one or two male faculty per workshop. Attendance at the workshops has varied from 9 to 25. 
Table 2: Workshops held at TCNJ during 2010/2011 academic year

\begin{tabular}{|c|c|}
\hline Date & Topic(s) \\
\hline October 19, 2010 & $\begin{array}{c}\text { Successful Scholarship and Family Life } \\
\text { Publishing and Handling Reviewers Comments } \\
\text { Developing a Circle of Mentors }\end{array}$ \\
\hline December 13, 2010 & $\begin{array}{c}\text { Involving Undergraduates in Research } \\
\text { Negotiation and Entitlement }\end{array}$ \\
\hline February 24, 2011 & Promotions Process and Best Practices \\
\hline May 24, 2011 & Grant Writing: Essential Steps and Best Practices \\
\hline
\end{tabular}

Following the model of the Hunter College workshops, the workshops have been interactive in nature, with small group discussions or role playing and interactive dialogue with the participants. Evaluation surveys are administered at the end of each workshop. The first one was a full day workshop; however, several participants indicated that it became hard to focus on the discussion by the end of the day. As a result, the other three workshops were half-day in length, which is intended to be the model of future workshops with some exceptions. Half-day workshops are also believed to increase attendance, as faculty do not have to block out an entire day, which also facilitates holding workshops on teaching days, although this is kept to a minimum. The fall workshops were held on either a day of Fall Break and/or end-of-semester Reading Day prior to final exams. The Promotions workshop was held in the morning of a teaching day, but was very well attended due to the nature of the topic. The final workshop of the year was held after graduation.

\section{Family Friendly Practices}

In the area of Family Friendly Initiatives there are two areas of work laid out. The first is to convene an ad hoc committee to investigate and promote current Family Friendly Policies at TCNJ, as well as to develop additional Family Friendly Policies to be considered through the College governance process. The second area of work is to establish more formal processes for the recruitment and retention of dual career couples. In the second year of the grant, much progress in the first area of work has been accomplished, while the work in the second area has progressed less rapidly.

An Ad Hoc Committee on Family Friendly Practices (CFFP) was formed in Spring 2010 , the committee reviewed several Modified Duties Policies developed at other institutions and initiated the process of developing such a policy at TCNJ. The committee, along with the Provost and the Vice-President of Human Resources, made a formal request to the College Steering Committee to request that the campus consider adopting a formal Modified Duties Policy. The Steering Committee has passed this work on to the Committee on Faculty Affairs and it is in line to be investigated early next academic year.

With regard to establishing processes for the recruitment and retention of dual career couples, the CFFP has begun working with the department of Human Resources. In the initial meeting with the director of Human Resources, the CFFP discussed the current role for the 
Human Resources office in the process of faculty recruitment. Two specific goals outlined in the proposal were the creation of a protocol for the recruitment of dual career faculty, as well as the designation of an HR specialist in the recruitment of dual career faculty. Because of constraints in both human and financial resources at TCNJ, these initiatives were lower in priority during Year 2. Hiring at TCNJ has been significantly curtailed in recent years, and notably, on the administrative side, as individuals have left TCNJ, their responsibilities have been shifted to other personnel. Thus, the administration and staff have been tremendously overburdened. During the third year of the grant, we plan to focus our efforts on utilizing the existing staff to devise a more formalized protocol, for both the role of HR in faculty recruitment and in establishing a process for establishing a "Dual Career Assistance Protocol".

\section{Conclusion}

After two years of running activities under this ADVANCE award, visibility and interest in the programs has been continuously building. We have been particularly encouraged by participation in events by Deans, the Provost, and several other administrators. Also encouraging has been the promotion of three female faculty in the School of Science to the rank of Professor since the start of the grant. While this cannot necessarily be directly attributed to the TAP Program, it is believed that a heightened awareness has been created among faculty who have learned about the program. These faculty can in turn become catalysts for current faculty who are preparing for promotion or other significant career moves, such as new leadership positions. The greatest challenge so far has been time. Many faculty are so involved in service that scheduling events when people are available can become a challenge and potential times during the semester are very limited. Overall, the programs offered under TAP have complemented each other and have created new opportunities for creating awareness of gender equity in STEM and ways to promote career advancement.

\section{Bibliography}

${ }^{1}$ National Academy of Sciences. 2007. "Beyond Bias and Barriers: Fulfilling the Potential of Women in Academic Science and Engineering." Washington, DC: National Academies Press.

${ }^{2}$ Roos, Patricia A. and Mary L. Gatta.. "Gender (In) Equality in the Academy: Subtle Mechanisms and the Production of Inequality." Research in Social Stratification and Mobility.

${ }^{3}$ Petersen, T and Saporta I. 2004. "The Opportunity Structure for Discrimination." American Journal of Sociology 109:852-901.

${ }^{4}$ Acker, Joan. 1990. "Hierarchies, Jobs, Bodies: A Theory of Gendered Organizations.” Gender \& Society 4, 2: 139-158.

${ }^{5}$ Rosser, S.V. 2004. The Science Glass Ceiling: Academic Women Scientists and the Struggle to Succeed. New York: Routledge.

${ }^{6}$ Sturm, S. 2006. "The Architecture of Inclusion: Advancing Workplace Equity in Higher Education." Harvard Journal of Law \& Gender 29:247-334. 